\title{
RELAÇÃO ENTRE O CONCEITO DE NATUREZA E SEQUESTRO DE CARBONO - APLICAÇÕES EM ÁREA DE SEMIÁRIDO
}

\author{
RELATIONSHIP BETWEEN THE CONCEPT OF NATURE AND CARBON SEQUESTRATION \\ - APPLICATIONS IN AREA OF SEMIARID
}

Luciana Mayla de Aquino FRANÇA', Valéria Sandra de Oliveira COSTA², Josiclêda Domiciano GALVÍNCIO³.

Palavras-chave: Natureza;

Filosofia da Natureza.

\begin{abstract}
RESU M O
A natureza vem sendo tratada de diversas formas ao longo do tempo, bem como vem obtendo conceitos cada vez mais divergentes em estudos de ciências humanas e ambientais. Correlacionar conceitos de natureza com temas atuais das ciências ambientais se faz importante como forma de compreender, de forma mais ampla, as interligações entre os fatores físicos do ambiente. Dessa forma, o objetivo do estudo é analisar e discutir alguns conceitos de natureza, considerando suas relações com conceitos e discussões sobre 0 sequestro de carbono em condições de semiárido. Os resultados apontam que os dois tópicos possuem interesses em comum.
\end{abstract}

\begin{abstract}
A B S T R A C T
This article analyzes, the socio-territorial implications resulting in the process of the expropriation carried by Vale in Nacala-a-Velha district. The article deals the matter in a qualitative manner, using descriptive and explorative methods. In analyzing the object of study, the bibliographical and documental researches were capitalized. Direct observation technics were applied as well as interviewing the representative of the two communities displaced by Vale in Nacala-a-Velha district. The results obtained from the research allowed us to understand that the resettlement program carried out by Vale in Nacala-a-Velha district is part of land grabbing, permitted by the government with the goal of allotting foreigners vast portions of land at the expense of the local communities who are taken to barren places, without water, schools, hospitals and other infrastructures, increasing the level of poverty.
\end{abstract}

Keywords:

Philosophy of Nature.

\footnotetext{
1 Doutoranda do Programa de Pós-Graduação em Desenvolvimento e Meio Ambiente (PRODEMA) da Universidade Federal de Pernambuco (UFPE). E-mail: lucianamayla@hotmail.com.

2 Professora Colaboradora, CAPES/PNPD-PRODEMA-UFPE. E-mail: costavso@yahoo.com.br.

3 Professora do Departamento de Ciências Geográficas da UFPE e do PRODEMA-UFPE. E-mail: josicleda@hotmail.com.
} 


\section{INTRODUÇÃO}

Desde os primórdios da humanidade vem sendo discutidas as implicações físicas, químicas e biológicas que envolvem a espécie humana e sua relação com o meio natural, também denominado de natureza.

Diversos estudiosos, ao redor do mundo, começaram a discutir o tema, principalmente através da publicação de pesquisas e teorias envolvendo essa temática, sobretudo nas questões que abordam os conceitos de natureza, sendo ela física ou humana, sua produção, formas de dominação e de evolução, dentre outras abordagens.

Em se tratando do tema abordado, é de fundamental importância o estudo do que concerne à relação primordial e mais antiga da nossa espécie, a relação que, desde o surgimento dos primeiros indivíduos homo, vem sustentando a evolução da espécie, principalmente através de técnicas, ainda que rudimentares, naquela época de dominação da natureza e da retirada de suprimentos que auxiliem a sobrevivência. Essa relação é denominada homem-natureza e se torna primordial para o bom entendimento do que será abordado neste estudo.

Nesse contexto, se fez de grande importância a definição de conceitos referentes à natureza e tudo 0 que a envolve no âmbito filosófico. A natureza pode ser, além do que foi citado, mágica ou racional. Segundo Neil Smith (1998), no livro Desenvolvimento Desigual, a natureza é:

material e espiritual, ela é dada e feita, pura e imaculada; a natureza é ordem e desordem, sublime e secular, dominada e vitoriosa, ela é uma totalidade e uma série de partes, mulher e objeto, organismo e máquina. A natureza é um dom de Deus e é um produto de sua própria evolução; é uma história universal a parte, e é também o produto da história, acidental e planejada, é selvagem e jardim (SMITH, 1998).

Este autor nos mostra a grande quantidade de significados que podem ser utilizados para a definição do termo, que John Passmore (1995) usa em um sentido mais restrito, "apenas incluindo aquilo que, deixando de lado o sobrenatural, designa o que não é humano, nem por si próprio, nem nas suas origens".

A natureza será abordada como meio físico, que está sob a ação direta das ações antrópicas, causando consequências devastadoras e irreversíveis para o ambiente ao qual se refere. № Brasil há diversas regiões fitogeográficas, divididas de acordo com a flora predominante. Uma dessas regiões é a caatinga, estabelecida sob um clima semiárido, que caracteriza uma área quente, onde predominam altas temperaturas, ocasionando altos índices de evaporação e evapotranspiração, com escassez de precipitação. Dessa forma, é uma região considerada inóspita e pobre por aqueles que desconhecem seu potencial. Desde tempos remotos, o homem vem fazendo observações sobre o clima bastante característico da região. No livro O Novo Mundo, de Antonio Gerbi (1996), o autor diz que: 
Neste estado de abandono, tudo se enlanguesce, tudo se corrompe, tudo sufoca: 0 ar e a terra, sobrecarregados de vapores úmidos e nocivos, não conseguem se depurar nem aproveitar-se das influências do astro da vida; o sol dardeja inutilmente seus mais vivos raios sobre a massa fria; esta não tem condições de responder a seu ardor; produzirá apenas seres úmidos, plantas, répteis, insetos, e somente poderá nutrir homens frios e animais débeis (GERBI, 1996).

Porém, ainda é bastante desconhecido, da população em geral, o potencial dessa região para a amenização de possíveis impactos das mudanças climáticas, fato que vem tomando maiores proporções nas últimas décadas, devido, principalmente, à emissão de gases poluentes causadores do fenômeno intitulado "efeito estufa". Esse fenômeno é causado pelo aumento dos níveis de gás carbônico $\left(\mathrm{CO}^{2}\right)$ na atmosfera, fazendo com que a radiação proveniente do sol não consiga retornar para o espaço e aqueça o planeta. Nessa abordagem, vêm surgindo novos debates no meio científico, principalmente sobre a utilização da expressão "sequestro de carbono", que consiste, em sua maioria, da retirada de gás carbônico da atmosfera através da fotossíntese das plantas. Alguns tipos de vegetação são mais eficientes que outros nesse tipo de processo. A vegetação de caatinga vem sendo estudada devido ao seu potencial relativo a essa abordagem, principalmente devido ao fato de emite poucos gases para a atmosfera e absorver uma grande quantidade dele, especialmente em se tratando do gás carbônico, durante os períodos de iluminação, para a fotossíntese. Devido a isso, se faz de extrema importância a preservação desse bioma e uma relação equilibrada entre ele e o homem.

\section{CONCEITOS DE NATUREZA E APLICAÇÕES}

Considerando o meio científico, sempre se fez necessária a definição de conceitos para que ocorra um bom embasamento teórico. Nesse sentido, foram buscados alguns conceitos de Natureza que podem ser aplicados ao contexto ambiental.

O próprio homem, ao intervir na Natureza, criando seu progresso a despeito desta, é a causa da sua degeneração (GERBI, 1996). Esse contexto se aplica diretamente ao que é visto no semiárido nordestino, onde o homem, através da intervenção na natureza, principalmente no que se refere ao desmatamento da mata nativa, para a implantação de outras culturas não nativas, causa a maior degradação vista no bioma. Essa chamada "degeneração" é o que causa as ampliações dos impactos ambientais em sua área de influência.

Segundo Gerbi (1996), contrastando com a afirmação anterior:

A natureza é externa, uma coisa, o reino dos objetos e dos processos que existem fora da sociedade. A natureza exterior é primitiva criada por Deus, autônoma; é a matéria prima da qual a sociedade é construída, a fronteira que o capitalismo industrial frequentemente faz recuar (GERBI, 1996). 
Nesse sentido, admite-se que exista uma natureza interior e outra exterior, onde a exterior seria aquela criada por Deus, impenetrável, sem modificações, e que o homem não deveria ter acesso, fato que foi sendo mudado ao longo do tempo. A natureza interior seria aquela ligada à natureza humana, fisicamente $e$ sentimentalmente, ligada ao caráter e à formação pessoal.

Considerando essa afirmação da natureza exterior, Passmore (1995) afirma que não é porque tudo foi feito para o homem, que o homem deva ir adiante e transformar o mundo. Ele também diz que "Deus sabe melhor do que é que precisamos. Tentar refazer o que Deus criou, é uma forma de atrevimento, de hubris. Homens pecadores e corruptos não devem tentar refazer o mundo a sua própria imagem".

Essa visão perdurou por algum tempo, porém, com o passar dos séculos, o homem começou a se aprofundar nas questões mecânicas, criando as rodas d'água, os moinhos de vento, o relógio e, com isso, a visão de natureza imutável foi sendo perdida. Como diz Passmore (1995), nenhum objeto natural era sagrado por si mesmo; não havia risco de sacrilégio em derrubar uma árvore, ou matar um animal. Continuando o pensamento do autor, ele afirma que: "A visão de que todas as coisas existem para servir o homem encorajou o desenvolvimento de um modo particular de ver a natureza, não como algo a ser respeitado, mas sim como algo a ser utilizado".

\section{PRODUÇÃO, DIVERSIFICAÇÃO, DOMINAÇÃO E ACUMULAÇÃO, SOB O CONTEXTO HOMEM- NATUREZA}

Nos primórdios da relação entre o homem e a natureza, ela se baseava nos conceitos religiosos, com a evolução e a necessidade de tirar o sustento da natureza, o homem começou a intervir, de forma direta, no meio circundante. Segundo Santos (1994), cada grupo humano construía seu espaço de vida com as técnicas que inventava, para tirar do seu pedaço de natureza os elementos indispensáveis à sua própria sobrevivência. Organizando a produção, organizava a vida social e organizava o espaço, na medida de suas próprias forças, necessidades e desejos. A cada constelação de recursos correspondia um modelo particular. Pouco a pouco esse esquema se foi desfazendo; as necessidades de comércio entre coletividades introduziam nexos novos e também desejos e necessidades, e a organização da sociedade e do espaço tinha de se fazer segundo parâmetros estranhos às necessidades íntimas ao grupo (SANTOS, 1994).

\subsection{PRODUÇÃO}

No contexto de produção da natureza há diversas divergências, principalmente no que se refere ao fato de que a Natureza não pode ser produzida, é a antítese da atividade produtiva humana (SMITH, 1988). 
De acordo com Smith (1998), Marx considerou a produção como um processo pelo qual se altera a forma da natureza. Ele ainda diz que:

O produtor só pode proceder como a própria natureza, isto é, apenas mudando as formas das matérias. Nesse trabalho de formação ele é constantemente amparado por forças naturais. Pela sua atividade, o homem modifica as formas das matérias naturais, de modo a torná-las úteis para ele (SMITH, 1998).

Ele continua afirmando:

Da produção em geral para a produção para troca e para a produção capitalista, as armas lógicas e históricas do argumento implicam e levam à mesma conclusa concretamente observável: a produção da natureza. Marx escreveu o seguinte: essa atividade, esse trabalho, essa criação material incessante dos homens, essa produção é a base de todo mundo sensível tal como hoje existe, e a tal ponto que se o interrompêssemos apenas por um ano, Feuerbach não só encontraria enormes modificações no mundo natural como até lamentaria a perda de todo o mundo humano e da sua própria faculdade de contemplação, ou mesmo de sua própria existência. As sociedades humanas agora produzem a natureza de modo tão completo que a cessação do trabalho produtivo provocaria alterações profundas na natureza, incluindo a extinção da natureza humana (SMITH, 1998).

Para concluir ele diz: "No capitalismo, a apropriação da natureza e sua transformação nos meios de produção ocorre em princípio em escala mundial. Dessa forma, somos levados a crer que o ser humano depende em larga escala da produção da natureza para a sua sobrevivência, os recursos que ela possui naturalmente não são suficientes para a sobrevivência da espécie, devido principalmente ao estado de torpor e relaxamento frente as facilidades encontradas através dessa produção".

\subsection{DIVERSIFICAÇÃO}

Segundo Milton Santos, em A Natureza do Espaço (2006), a diversificação da natureza é:

Processo pelo qual se constituem entidades a que chama de elementos naturais, produtos cujas características derivam a cada movimento do respectivo modo de diversificação. A um modo de diversificação sucede outro modo de diversificação. É assim que a natureza faz-se outra, enquanto mudam os seus aspectos e ela própria muda como um todo (SANTOS, 2006).

Ainda, segundo o mesmo autor, os diversos momentos da diversificação da natureza criam padrões específicos que a definem. A natureza não segue um padrão lógico de evolução ou modificação, ela se mostra cada vez mais diversificada ao olhar humano, ocasionando ainda mais modos de dominação por parte da nossa espécie.

Com a evolução da espécie, o homem cada vez mais começou a atuar na diversificação da natureza, muitas vezes através de invenções e processos criativos, tornando a natureza um espaço construído socialmente, principalmente após a expansão vertiginosa do capitalismo. Sobre isso, Santos (2006) diz: 
A primeira presença do homem é um fator novo na diversificação da natureza, pois ela atribui às coisas um valor, acrescentando ao processo de mudança um dado social. Num primeiro momento, ainda não dotado de próteses que aumentem seu poder transformador e sua mobilidade, o homem é criador, mas subordinado. Depois, as invenções técnicas vão aumentando o poder de intervenção e a autonomia relativa do homem, ao mesmo tempo em que se vai ampliando a parda da "diversificação da natureza" socialmente construída.

Com a marcha do capitalismo, amplia-se a tendência a que, sobre a diversificação da natureza, operada pelas forças naturais, se realize outra diversificação, também a escala global, mediante forças sociais (SANTOS, 2006).

\subsection{DOMINAÇÃO E ACUMULAÇÃO}

A relevância dos fatores naturais tem sido tradicionalmente objeto de atenção e as diversas propostas de explicação dessa influência alimentaram, durante este século, um vivo debate interno na geografia humana. Mas a questão do meio ambiente construído, tornada, recentemente, uma moda, está ainda muito longe de se esgotar e muito terá a ganhar se levarmos em conta o papel das formas no processo social (SANTOS, 2006).

O princípio da dominação se ergue sob a base de que a natureza serve os seres humanos como meio de subsistência e a espécie deverá extrair dela tudo o que for necessário para continuar com a evolução do sistema, não levando em consideração os impactos decorrentes. Dessa forma, Lefebvre (2004) diz:

Por volta do ano 2000, com ou sem uma guerra nuclear, a água e 0 ar estarão poluídos a tal ponto que a vida tornar-se-á difícil na terra. Os bens outrora raros tornam-se abundantes: o pão e os alimentos em geral (ainda raros numa grande parte mal desenvolvida do planeta, mas superabundantes na parte desenvolvida). Ao contrário, os bens outrora abundantes tornam-se raros: o espaço, o tempo, o desejo. $E$ depois a água, a terra, a luz. Não se imporá a gestão coletiva das novas raridades? A não ser que se imponha a produção ou reprodução de tudo que foi a natureza (LEFEBVRE, 2004).

Considerando a questão da acumulação, os estudos se referem, principalmente, ao processo acumulativo de conhecimentos, técnicas, riquezas, dinheiro e capital. Esses processos são bastante interessantes, quando levadas em consideração as interligações entre o campo e a cidade, pois o campo seria retratado como o meio produtor e a cidade como o meio consumidor dessa produção campestre. Porém, com a evolução e a tecnificação dos centros urbanos, essa produção passou a ser inserida nos centros das cidades. Segundo Lefebvre (2004), é desde esse momento que a cidade aparece como segunda natureza, pedra e metal, erigida sobre a natureza inicial e fundamental, a dos elementos, a terra e 0 ar, a água e o fogo. 


\section{RELAÇÃO ENTRE NATUREZA, SEQUESTRO DE CARBONO E LOCALIZAÇÃO GEOGRÁFICA}

Quando os homens atuam sobre a natureza, eles não modificam simplesmente uma qualidade particular de uma substância particular. O que eles fazem realmente é interagir com um sistema de interações, colocando em andamento novas interações. É precisamente por essa razão que existe sempre 0 risco de que suas ações tenham consequências por eles não previstas (PASSMORE, 1995).

O termo Sequestro de Carbono foi consagrado durante a Conferência de Kyoto, em 1997, que visou 0 estabelecimento de metas de redução das emissões dos gases poluentes por parte dos países industrializados.

Estudos de avaliação dos impactos das mudanças climáticas sobre a estabilidade dos biomas predominantes no Brasil (OYAMA \& NOBRE, 2003) indicam que o bioma caatinga está entre os mais vulneráveis em um cenário de aumento das temperaturas globais, o que coloca a região nordeste do Brasil em estado especial de alerta (NOBRE, 2011).

Segundo Santos et al. (2000), o nordeste brasileiro dispõe de recursos de água, irregularmente distribuídos no tempo e no espaço, em decorrência de fatores meteorológicos e geomorfológicos desfavoráveis, sendo necessárias medidas especiais para o uso adequado de suas potencialidades. Quando não há água disponível no solo, ocorre o estresse hídrico. A elevada exigência de água, portanto, é intrínseca da planta, que, se não satisfeita, afeta o crescimento e a produção (PIRES et al., 2008). Este fato pode ser corroborado através do que Gerbi (1996) afirma:

Mais tarde, Hegel, polemizando sobre a concepção de que a natureza viva se desenvolve no tempo, através dos séculos e dos milênios (e abandonando assim os princípios de historicismos já existentes em Buffon), arremeterá contra a "nebulosa" suposição de que os animais e plantas vieram da água. Mas, se projetamos aquelas crenças sobre o profundo passado ao qual pertencem, seremos forçados a reconhecer que a visão da Vida como derivada da água é talvez a mais antiga das explicações científicas e um dos mais remotos mitos da humanidade (GERBI, 1996).

Como citado ao longo deste estudo, com o tempo, o ser humano começou a aprimorar suas técnicas mecânicas e a construir equipamentos para auxiliar no controle e domínio da natureza. Um desses equipamentos foram os satélites artificiais, que vêm sendo bastante utilizados, desde o final da década de 1970, para o monitoramento ambiental e, consequentemente, para a elaboração de estudos técnicos abordando a degradação ambiental e diferentes formas de análise.

Por fim, Passmore (1995) descreve, perfeitamente, o que acontece, atualmente, relativo a essa questão:

0 argumento reza que os homens têm que reconhecer que eles formam uma comunidade com as plantas, os animais, a biosfera e que todos os membros dessa comunidade têm direitos - inclusive o direito de viver e o direito de serem tratados com respeito. Em oposição a essa doutrina os estoicos tem argumentado, há muito tempo, que desta forma a 
civilização será impossível, e que os seres humanos não poderiam nem sobreviver se os homens fosses obrigados a atuar de forma justa com a natureza.

Assim, não podemos aceitar o argumento de que o que aconteceu no mundo apenas é: 0 homem, como espécie dominante, destruindo, numa competição biológica normal, outras espécies competitivas, e que atormentar-se pelo fato do desaparecimento destas espécies é tão absurdo quanto lamentar que o mundo não contenha mais dinossauros. É verdade que, como qualquer outra espécie, os homens só podem sobreviver à custa de outras espécies. Mas os homens podem ver o que está acontecendo; eles podem observar 0 desaparecimento das espécies em concorrência; eles podem avaliar as consequências deste desaparecimento; eles podem - pelo menos em princípio - preservar uma espécie e modificar seu próprio comportamento de forma a torná-lo menos destrutivo. Que de várias e fundamentais maneiras os homens não sejam sem igual é o ponto de partida de uma metafísica satisfatória. Mas em outros sentidos eles são sem igual. Uma "nova metafísica", para não falsificar os fatos, terá que ser naturalista, mas não reducionista. A elaboração desta metafísica é, na minha opinião, a tarefa mais importante proposta à filosofia (PASSMORE,1995).

\section{CONSIDERAÇÕES FINAIS}

O homem moderno interage, de forma direta, com a natureza, extraindo seus recursos da forma mais predatória possível, ocasionando a extinção de espécies animais e vegetais, a erosão do solo, o aumento da temperatura média global, além da emissão exacerbada de gases poluentes altamente nocivos para os homens e a atmosfera. Todos esses fatores interligados ocasionam as mudanças climáticas e ampliam seus efeitos. Esse conceito se adéqua perfeitamente ao que alguns autores citam como "natureza vingativa", ou seja, depois de séculos de degradação, a natureza se volta contra o homem para ter de volta tudo o que dela foi retirado.

O termo "mudanças climáticas" começou a ser difundido na comunidade científica após a conferência das partes e a realização do Protocolo de Kyoto e estima-se que a região mais afetada será a Nordeste do Brasil, devido, principalmente, a vulnerabilidade da sua vegetação. Dessa forma, se faz necessária a realização de estudos para amenizar esses impactos, ao menos em nível local. Uma forma de realizar isso é através da preservação da vegetação, pois, através da fotossíntese ela absorve o gás carbônico presente na atmosfera e, quando perde as folhas na estação seca, em consequência da morte deste órgão vegetal devido a uma intensa desidratação pela evapotranspiração, deixa de emitir este gás de volta para a atmosfera. Este comportamento é mais acentuado na vegetação de caatinga, em função da elevada temperatura e escassa precipitação, levando a uma intensa perda de água durante a fotossíntese.

Com isso, vemos a importância da interligação entre o contexto histórico-filosófico da natureza natural e os impactos ambientais causados pelo processo vigente de degradação que se iniciou há milênios, através da perda da visão humana da natureza como algo mutável e sensível ao desequilíbrio. 


\section{AGRADECIMENTOS}

Agradeço a Fundação de Amparo a Ciência e Tecnologia do Estado de Pernambuco (FACEPE) e a Coordenação de Aperfeiçoamento de Pessoal de Nível Superior (CAPES) pela concessão de bolsa de pósgraduação através do edital 17/2016 PBPG 2017.1 - FACEPE

\section{REFERÊNCIAS}

GERBI, A. O Novo Mundo: história de uma polêmica (1750-1900). São Paulo: Companhia das Letras, 1996.

LEFEBVRE, G. A revolução urbana. Trad. Sérgio Martins. Belo Horizonte: Editora UFMG, 2004.

NOBRE, P.; MALAGUTTI, M.; URBANO, D. F.; ALMEIDA, R. A. F. DE; GIAROLLA, E. Amazon deforestation and climate change in a coupled model simulation. Journal of Climate, v. 22, p. 5686-5697, 2009.

OYAMA, M. D.; NOBRE, C. A. 2003. A new climatevegetation equilibrium state for Tropical South America. Geophysical Research Letter, vol. 30, n. 23, p.2199, 2003.

PASSMORE, J. Atitudes frente a natureza. Revista de Geografia. Recife: UFPE, v. 11, n. 2, jul./dez/, p. 91102, 1995.

SANTOS, J. S.; MASSARO, E. O. S. Avaliação da salinização de açudes no semi-árido brasileiro por ICPAES. Quím. Nova, v. 23, n. 4, p. 453-456. 2000.

SANTOS, M. A Natureza do Espaço: Técnica e Tempo, Razão e Emoção. São Paulo: Editora da Universidade de São Paulo, 2006.

SANTOS, M. Técnica, Espaço, Tempo: Globalização e meio técnico-científico-informacional. São Paulo.

Hucitec, 1994.

SMITH, N. Desenvolvimento Desigual: natureza, capital e a produção do espaço. Trad. Eduardo de Almeida Navarro. Rio de Janeiro: Bertrand Brasil, 1988. 